\title{
Primeiro Relato de Ocorrência da Sigatoka-Negra em Minas Gerais
}

\author{
Maria Eunice A. Castro ${ }^{1}$, José Clério R. Pereira ${ }^{2} \&$ Luadir Gasparotto $^{2}$ \\ ${ }^{1}$ IMA/DDSV, Av. dos Andradas, 1220, CEP 30120-010, Belo Horizonte, MG; ${ }^{2}$ Embrapa Amazônia Ocidental, \\ Cx. Postal 319, CEP 69011-970, Manaus, AM
}

(Aceito para publicação em 17/03/2005)

Autor para correspondência: José Clério R. Pereira

\begin{abstract}
First Report of black-sigatoka in the State of Minas Gerais, Brazil

Back-sigatoka caused by Mycosphaerella fijiensis is the most economically important disease of banana (Musa spp.) and plantain. Mycosphaerella fijiensis causes early defoliation resulting in yield losses of about $100 \%$ in common bananas such as Prata, Prata Anã and Cavendish cultivars. Black-sigatoka has been occurring in the State of Minas Gerais since July 2004.
\end{abstract}

A sigatoka-negra causada por Mycosphaerella fijiensis Morelet anormorfo Paracercospora fijiensis (Morelet) Deighton, é a doença mais destrutiva da bananeira (Musa spp.) e plátanos. A doença causa morte prematura das folhas com reflexos significativos na produção; podendo atingir, nas cultivares dos subgrupos Prata e Cavendish, perdas de $100 \%$, a partir do primeiro ciclo produtivo.

A identificação da doença foi processada com base nos sintomas em folha das cultivares Prata, Prata Anã, Nanica e Nanicão e exames ao microscópio ótico confirmando-se a presença do fungo $P$. fijiensis nas lesões ou manchas foliares.

Os conidióforos de P. fijiensis são produzidos isoladamente ou em pequenos grupos, dois a oito, são retos ou ligeiramente curvos, coloração clara a marrom-claro, com zero-cinco septos, freqüentemente geniculados; raramente ocorre ramificação na base e apresentam cicatrizes do esporo proeminentes, e medem 16,5 - 6,25 $\mu \mathrm{m}$ x $4-7 \mu \mathrm{m}$. Os conídios são predominantemente obclavados a obclavados cilíndricos, retos ou curvos, hialinos a claro-oliváceos, com um a dez septos, mais comumente cinco septos e apresentam hilo basal conspícuo (Frossard, P. Fruits, vol 35, no. 9, 1980). Nas folhas a doença é caracterizada pelo surgimento de estrias de coloração marrom-claro na face abaxial que se expandem radial e longitudinalmente, adquirem coloração marromescura a negra e se transformam em manchas de formato irregular (Figura 1) e, diferentemente do que ocorre na sigatoka-amarela, não ocorre necrose no limbo foliar nos sítios de infecção. A coalescência de várias manchas induz a morte prematura das folhas.

A doença foi identificada nos municípios de Cristina, São José Alegre, Gonçalves e Piranguçu, no Sul de Minas e Coronel Pacheco, zona da Mata Mineira.

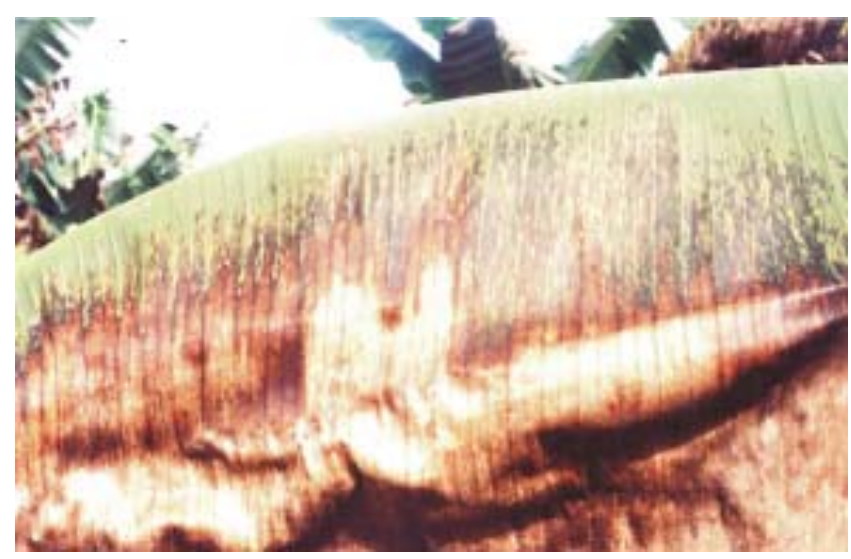

FIG.1 - Sintomas característicos da sigatoka-negra em folha de bananeira (Musa spp.). 